\title{
Percepção e julgamento da retaliação organizacional: construção e validação fatorial de um instrumento
}

\author{
Helenides Mendonça \\ Universidade Católica de Goiás \\ Dulce Pires Flauzino \\ Universidade Federal de Uberlândia \\ Álvaro Tamayo \\ Maria das Graças Torres Paz \\ Universidade de Brasília
}

\begin{abstract}
Resumo
Este artigo apresenta dois estudos sobre a construção e a validação de um instrumento de medida da percepção e do julgamento da retaliação organizacional. No primeiro estudo, a escala composta inicialmente por 31 itens foi aplicada a uma amostra de 187 sujeitos. Os dados foram submetidos à análise fatorial e eliminaramse os itens que não alcançaram o critério de carga fatorial estipulado, permanecendo 15 itens na solução final. Os resultados apontam uma estrutura unifatorial para a percepção $(\alpha=0,95)$ e para o julgamento da retaliação $(\alpha=0,89)$. No segundo estudo $(N=313)$, a análise fatorial confirmatória reafirma a estrutura fatorial obtida. As escalas de percepção e julgamento demonstram validade fatorial com índices de precisão que as indicam para aplicações no âmbito científico e, comparadas a estudos anteriores, apresentam avanços que vão de uma concepção comportamental para uma concepção perceptiva e avaliativa da retaliação organizacional.
\end{abstract}

Palavras-chave: medida de percepção e julgamento da retaliação; reações à injustiça; retaliação organizacional

\begin{abstract}
Perception and judgment of organizational retaliation: construction and factorial validation of an instrument. This article presents two studies about the construction and validation of an instrument to measure the perception and the judgment of the organizational retaliation. In the first study, the scale initially composed by 31 items was applied to a sample of 187 subjects. Data were submitted to factor analysis and the items that did not achieve the established criterion of factor charge were eliminated, so that in the final solution there were 15 remaining items. The results point to a one-factor structure for perception $(\alpha=.95)$ and for retaliation judgment $(\alpha=.89)$. In the second study $(N=313)$, the confirmatory factor analysis reaffirms the factorial structure obtained. The scales of perception and judgment demonstrate factorial validity with precision indexes that indicate them to be applied in the scientific sphere, which, compared to previous studies, present advances from a behaviorist conception to a perceptive and evaluative conception of the organizational retaliation.
\end{abstract}

Keywords: measure of perception and judgment of retaliation; reactions to injustice; organizational retaliation

$\mathrm{O}$ s estudos empíricos na área de comportamento organizacional abrangem, em sua maioria, as ações positivas e bem aceitas no contexto sócio organizacional. A literatura nessa área do conhecimento tem negligenciado os comportamentos disfuncionais no trabalho, como a retaliação. Este artigo, no entanto, busca compreender a natureza perceptiva e avaliativa da retaliação. Primeiramente, analisa-se a realidade social na qual as organizações estão inseridas, discutem-se alguns processos sócio organizacionais que podem levar à emissão de comportamentos de retaliação e demonstra-se a necessidade de obter instrumentos de medida adequados para investigar esse construto, que é real e pode trazer grandes prejuízos para a eficácia organizacional. Em seguida, apresenta-se o estudo empírico.

O primeiro ponto a ser considerado é que a redução de investimentos em quantidade de pessoas empregadas, fato crescente quando consideradas as três revoluções tecnológicas vividas mundialmente, tem levado os trabalhadores cada vez mais a romper os laços de lealdade que, historicamente, os uniam aos seus empregadores. No caso dos ocupantes de níveis gerenciais, eles têm mudado os seus focos de lealdade. Os indivíduos com valores existenciais 
estão alterando seu foco de lealdade para eles próprios e os pragmáticos, para as suas carreiras (Robbins, 1999). Uma explicação possível para isso consiste no fato de que, diante da não oferta e da dificuldade de manutenção de empregos, os trabalhadores têm retirado os seus investimentos da organização. Um desses investimentos é a lealdade à organização e aos empregadores.

Outro investimento que pode ser retirado é o comprometimento organizacional afetivo. De acordo com Mowday, Poter e Steers (1982), o indivíduo pode estabelecer uma relação ativa no sentido de identificar-se com a organização, desejando manter-se como seu membro para obter a satisfação de seus interesses. Todavia, pressupõe-se que, ao sentir a ameaça à realização desse desejo em virtude da perspectiva da não garantia da manutenção de seus empregos, os trabalhadores podem deixar de se envolver e de se comprometer ativamente com suas organizações. Como os laços de lealdade estão cada vez mais frágeis, o trabalhador pode ter maior facilidade em desfazer o seu vínculo com a organização, o que é denominado rotatividade voluntária (Siqueira \& Pereira, 2001).

O terceiro investimento que o trabalhador pode retirar da organização são os comportamentos de cidadania organizacional, os quais representam os comportamentos individuais que são discricionários, não direta ou explicitamente reconhecidos pelo sistema de recompensas formais e que promovem o funcionamento efetivo das organizações (Siqueira, 1995).

Os planejamentos organizacionais não possibilitam prever com precisão todas as contingências, como a variabilidade humana e as mudanças ambientais. Assim, os comportamentos inovadores e espontâneos, não prescritos nos papéis organizacionais, podem fortalecer o sistema social e os comportamentos de retaliação, ao contrário, estimulam a fragilidade da organização.

A análise desses fenômenos aponta para o fato de que quando as organizações rompem uma relação de troca com seus trabalhadores, estes buscam retirar os seus investimentos.

Concebendo o comportamento social como uma troca de bens materiais e não-materiais, Adams (1965) postulou a teoria da ineqüidade ${ }^{1}$. De acordo com ela, ao fazer comparações sociais e perceber que a situação analisada viola as suas expectativas, os indivíduos tendem a reagir de alguma maneira. Uma das formas de eles reagirem é pela utilização de estratégias que lhes permitam recuperar o equilíbrio cognitivo. Essas estratégias consideram tanto as discrepâncias percebidas quanto o contexto no qual o indivíduo vivencia a inequiidade.

Na análise de Gomide Jr. (1999), as situações de ineqüidade levam à tensão e o indivíduo busca restaurar a eqüidade como forma de se livrar dela, fazendo isso de três maneiras: modificando as suas contribuições e/ou recompensas, modificando as do outro participante ou, ainda, distorcendo psicologicamente suas percepções. Em seu estudo, o autor conclui que os indivíduos experimentadores de maior tensão numa relação iníqüa tentarão restaurar a eqüidade de três formas: buscando compensações, contra-atacando o seu algoz ou lançando mão de distorções para recuperar a eqüidade.

Analisando o contra-ataque ao algoz, Hollinger e Clark (1983) demonstram que o empregado se engaja em ações con- tra a organização quando se sente explorado. Para Homans (1961), os indivíduos que ocupam posições hierárquicas inferiores tendem a emitir ações contra a organização de forma indireta, dissimulada e sutil. Esse tipo de retaliação, apesar de pouco agressivo, apresenta fortes conseqüências para a efetividade organizacional.

Jermier, Knights e Nord (1994) verificaram, adicionalmente, que indivíduos menos poderosos em relação à fonte da injustiça percebida tendem a se engajar, inicialmente, em comportamentos sutis de retaliação (retirada de comportamentos de cidadania, retirada psicológica da situação ou da emissão de comportamentos de resistência) para, depois, assumir comportamentos diretos de retaliação (furto, sabotagem, dentre outros).

Procedendo-se a uma análise da literatura sobre comportamento organizacional verifica-se uma predominância de estudos que enfocam prioritariamente comportamentos e atitudes socialmente aceitos (cidadania, civismo e comprometimento organizacional, dentre outros), sendo especialmente voltados para a identificação de antecedentes de mesma natureza. Todavia, poucos estudos têm enfocado a possibilidade de as pessoas deixarem de emitir tais comportamentos em função das injustiças percebidas. Assim, além de buscar os antecedentes para a instalação de tais comportamentos devem ser compreendidos fenômenos que possam interferir em sua manutenção. Um deles refere-se ao fenômeno da retaliação.

Skarlicki e Folger (1997) realizaram um estudo, denominado por eles Comportamentos de Retaliação Organizacional (CRO), enfocando os comportamentos negativos utilizados pelos empregados para punir a organização e seus representantes pelas injustiças sentidas e percebidas pelos trabalhadores. Os autores construíram uma Escala de Observação Comportamental utilizando a técnica dos incidentes críticos $(\alpha=0,97)$, abrangendo o aspecto comportamental da retaliação; porém, ela foi construída e validada levando em consideração a realidade de uma única organização, o que dificulta a generalização para outros contextos.

Os autores do presente trabalho, entretanto, ao supor que a forma da retaliação pode variar de acordo com a natureza e as oportunidades específicas de um dado contexto, optaram por construir e validar um instrumento para a medida da retaliação adequado à realidade nacional e utilizando diferentes organizações, a fim de aumentar o seu poder de generalização. A escala utilizada neste estudo foi construída com base naquela de Skarlicki e Folger (1997), desenvolvida em um contexto canadense.

O presente estudo buscou desenvolver uma medida que abarque não apenas a frequiência comportamental da retaliação, como o faz a escala de Skarlicki e Folger (1997), mas também as dimensões perceptivas e avaliativas desse comportamento. Com isso, pretende-se contribuir para a melhor compreensão de comportamentos disfuncionais que podem dificultar a manutenção de atos socialmente aceitos. A retaliação é concebida, neste estudo, como um comportamento que ocorre sutilmente em resposta à injustiça no trabalho e é emitido contra a organização ou as pessoas que dela fazem parte.

Foi adotado o procedimento de registrar a percepção que os indivíduos têm em relação à emissão dos comportamentos 
de retaliação devido ao fato de que os indivíduos relutam em registrar seus próprios comportamentos disfuncionais com medo de ser repreendidos (Murphy, 1993). Para analisar comportamentos suscetíveis à desejabilidade social, como a retaliação organizacional, McEvoy e Buller (1987) demonstram que é mais válido e confiável medir os comportamentos relatados pelos pares.

De fato, desde Lewin (1935), a percepção que as pessoas têm do mundo que as cerca possibilita a melhor compreensão do comportamento do que as descrições objetivas dos estímulos ambientais. Outros autores reforçam a opção teórico-metodológica para o estudo da percepção, como Allport, Vernon e Lindsey (1960), para quem as causas do comportamento social são duplamente cognitivas, englobando as percepções individuais presentes e a imaginação das suas presenças. Fiske e Taylor (1991) defendem que as reações das pessoas predizem suas percepções e não as simples ações, desprovidas de significado. Uma recompensa em dinheiro, por exemplo, pode ter uma dupla conotação: suborno ou justo reconhecimento. A percepção subjetiva da recompensa, como atitude manipulatória, influencia diferentemente se a ação for percebida como desprovida de tal intenção.

Utilizando a mensuração individual de atributos perceptuais, a retaliação é vista como a percepção global da organização, investigada pela ótica dos indivíduos que a compõem. Segundo James e James (1989), a interação entre características pessoais e organizacionais compõe a percepção global. Schneider (1985) entende que o resultado da interação do indivíduo com o seu ambiente organizacional não se restringe a uma simples soma da percepção de diversas partes. Essa interação constitui-se na percepção global, que é composta por um todo dinâmico passível de obter estrutura psicologicamente significativa.

O presente estudo buscou, assim, desenvolver uma escala que possibilite compreender os comportamentos sutis de retaliação a partir da percepção e do julgamento da retaliação organizacional.

\section{Construção da medida}

O presente estudo foi executado em duas etapas. A primeira delas foi estruturada com dois objetivos específicos: desenvolver uma análise exploratória com a finalidade de investigar se a representação que os trabalhadores brasileiros, mais especificamente de Goiânia-GO, fazem dos comportamentos de retaliação é a mesma que foi apresentada no estudo de Skarlicki e Folger (1997), com trabalhadores canadenses; e realizar um estudo-piloto para investigar se a melhor maneira de medir a retaliação é por meio da utilização de medidas comportamentais diretas, de intenção comportamental ou de percepção e julgamento.

$\mathrm{Na}$ primeira etapa do estudo buscou-se levantar dados empíricos sobre os comportamentos e as reações sutis emitidos pelos empregados quando sentem que estão sendo tratados injustamente no trabalho e, sobretudo, desenvolver uma medida adequada para a análise da retaliação organizacional.
Na segunda etapa, e com base no resultado do estudopiloto, procedeu-se à validação fatorial da escala de percepção e julgamento da retaliação.

Para cumprir os objetivos estabelecidos na primeira etapa e construir a medida validada neste estudo foram executados os seguintes passos:

(a) Com o objetivo de criar uma medida capaz de abarcar todas as propriedades do construto, os itens foram levantados em duas organizações com características diferentes, uma instituição pública e uma privada, para aumentar a variabilidade da amostra;

(b) Os itens da escala foram levantados solicitando-se a dois grupos independentes em cada uma das organizações (composto por funcionários efetivos com mais de dois anos de tempo de serviço), que identificassem comportamentos que pudessem ser definidos como de retaliação contra a organização ou contra alguém que dela faz parte;

(c) Foi entregue aos participantes a seguinte definição de retaliação: "Pesquisas sugerem que quando as pessoas percebem que estão sendo tratadas injustamente no trabalho tendem a encontrar formas de contra-atacar e descontar. Essa retaliação pode ser direta ou indireta e pode ser direcionada à organização ou a alguém dentro dela" (Skarlicki \& Folger, 1997);

(d) Em seguida solicitou-se aos participantes que pensassem nos últimos 12 meses de trabalho e apontassem exemplos de comportamentos que observaram naquele período que se enquadravam na definição dada a eles; os sujeitos anotavam o que a pessoa fizera e porque considerou esse exemplo como retaliação; foi pedido que cada sujeito apresentasse dez incidentes críticos (Flanagan, 1954);

(e) Foram selecionados os incidentes comuns em cada um dos grupos; com base nos dados coletados, levantaram-se os itens que deram origem à primeira versão do instrumento;

(f) Em seguida, o instrumento foi submetido à validação semântica num grupo contendo indivíduos com segundo grau completo, sendo efetuadas as correções que se fizeram necessárias; e

(g) O instrumento passou pela análise de cinco juízes, todos psicólogos com experiência na área organizacional, chegando à versão final com 31 itens; nesse processo foram mantidos os itens do instrumento de Skarlicki e Folger (1997), ficando fora apenas um dos 17 itens do instrumento canadense (Levar material de consumo para casa sem permissão), e acrescentados outros 15 itens.

\section{Estudo-piloto}

O estudo-piloto foi realizado para possibilitar o desenvolvimento de uma medida que conseguisse superar as dificuldades encontradas pelos indivíduos em auto-relatar comportamentos desviantes. Essa dificuldade ocorre em razão do potencial para repreensões a que os trabalhadores estão sujeitos quando admitem que reagem contra a injustiça percebida (Skarlicki \& Folger, 1997; Skarlicki, Folger, \& Tesluk, 1999).

O objetivo básico do estudo-piloto foi verificar se os sujeitos manifestavam relutância em responder a três tipos 
de instrumentos com os mesmos itens, mas diferentes no estímulo para a resposta. A primeira escala é uma medida de freqüência comportamental; a segunda, de intenção comportamental; e a terceira possui duas escalas, uma sobre a percepção de retaliação e a outra para investigar o julgamento acerca dos comportamentos de retaliação organizacional.

O primeiro instrumento utilizado na pesquisa-piloto é uma escala de medida comportamental construída conforme os procedimentos estabelecidos por Likert, com 5 pontos, em que 1 corresponde a nunca e 5, a sempre. O estímulo para a emissão das respostas é que os sujeitos relatem a freqüência com que eles emitiram cada um dos comportamentos especificados no último ano.

O segundo instrumento é uma escala de intenção comportamental, também construída no modelo Likert de 1 (nunca) a 5 (sempre), solicitando que os sujeitos apontem as formas de reagir que melhor caracterizem o que eles acham que fariam, ou têm vontade de fazer, quando se sentem vítimas de injustiça.

O terceiro instrumento compõe-se de duas escalas, organizadas em duas colunas. A primeira escala, no modelo Likert, variando de 1 (nunca) a 5 (sempre), solicita que os sujeitos relatem a freqüencia com que as pessoas daquela organização se comportam da forma descrita (em cada frase) quando elas se sentem injustiçadas no trabalho. Na outra escala, também no formato Likert de 5 pontos, variando de 1 (muito injusto) a 5 (justíssimo), a pessoa deveria assinalar o quanto considera justo o fato de as pessoas agirem daquela forma diante das injustiças sofridas no trabalho.

Os dados obtidos na pesquisa-piloto foram submetidos, para análise preliminar, ao programa estatístico SPSS (Statistical Package for the Social Sciences) versão 8.0. Utilizou-se a técnica estatística ANOVA com o objetivo de verificar a variabilidade entre as médias obtidas nos três instrumentos aplicados. A comparação das médias demonstra maior variabilidade no instrumento que se refere à percepção e ao julgamento do comportamento de retaliação, que é o terceiro instrumento. $\mathrm{O}$ teste Scheffe apresenta diferenciação apenas para a terceira versão da medida.

Considerando esses resultados, optou-se pela medida perceptiva e avaliativa da retaliação (terceiro instrumento) para realizar a validação psicométrica.

\section{Estudo 1: Validação fatorial das escalas: "Percepção de retaliação organizacional" e "Julgamento da retaliação"}

O objetivo deste estudo é analisar a validade fatorial da EPJRO (Escala de Percepção e Julgamento da Retaliação Organizacional) e aferir a precisão de seu(s) fator(es), desenvolvendo uma medida para uso no Brasil. Foi preocupação do estudo buscar obter a participação de sujeitos que representassem o maior número possível de diferentes organizações. Para atingir tais objetivos, foi desenvolvido um estudo cujos procedimentos, análises aplicadas aos dados, resultados e discussão estão descritos a seguir.
Método

\section{Amostra}

Este estudo teve uma amostra composta por trabalhadores $(N=187)$ selecionados aleatoriamente, os quais fazem parte da iniciativa privada $(57,8 \%)$ e do setor público $(30,5 \%)$. Dentre os respondentes, $11,7 \%$ não identificaram se a organização em que trabalham é pública ou privada. A amostra foi obtida em universidades, instituições públicas e organizações privadas, buscando-se uma amostra mais geral e representativa dos trabalhadores goianienses. A idade dos respondentes variou entre 18 e 57 anos, com média de 30,32 anos $(D P=9,29)$, com grau de escolaridade variando do ensino médio completo $(12,8 \%)$ à pós-graduação $(5,8 \%)$.

\section{Instrumento}

Foi entregue aos respondentes um questionário contendo explicações sobre o estudo na primeira folha e nas folhas seguintes as escalas compostas por 31 itens. Esses itens foram respondidos em duas colunas.

$\mathrm{Na}$ primeira coluna utilizou-se uma escala de 5 pontos, variando de 1 (nunca) a 5 (sempre), a ser respondida considerando a experiência pessoal do respondente. Foi pedido que os sujeitos apontassem a freqüência com que as pessoas, na empresa em que trabalham, ao se sentirem injustiçadas, comportam-se da maneira descrita nas frases. Nessa coluna objetivou-se investigar a percepção de retaliação.

Na segunda coluna também se utilizou uma escala de 5 pontos, variando de 1 (muito injusto) a 5 (justíssimo). Pediuse que os respondentes expressassem suas opiniões pessoais e julgassem os comportamentos descritos nas frases. Essa coluna foi construída com o objetivo de investigar a atribuição de justiça ao comportamento de retaliação.

\section{Procedimento}

$\mathrm{O}$ instrumento foi aplicado nos trabalhadores coletivamente, durante o horário de trabalho ou de aula. A aplicação foi realizada em organizações públicas, empresas particulares e instituições de ensino superior. No caso das instituições de ensino superior, participaram do estudo apenas os estudantes que trabalham e que estivessem vinculados à mesma organização há mais de dois anos.

\section{Resultados}

A validação da escala foi realizada por meio do programa SPSS (Statistical Package for the Social Sciences) versão 8.0. Utilizou-se a técnica estatística análise fatorial para levantar a estrutura fatorial da medida. Empregou-se o método dos componentes principais (eigenvalue superior a 2,0). Aplicou-se, primeiramente, a rotação oblimin (método oblíquo) e, posteriormente, a rotação varimax (método ortogonal). Para obter a matriz rotada foi estipulado o critério de carga fatorial mínima de 0,40 para a inclusão dos itens. Foram eliminados os itens que não alcançaram o critério de carga fatorial estipulado, permanecendo na solução final 15 itens que foram submetidos à mesma técnica de análise. A versão final da escala encontra-se no Apêndice. 
Os resultados são apresentados em duas seções. A primeira descreve os dados referentes à percepção de retaliação organizacional e a segunda descreve os dados que se referem ao julgamento dos trabalhadores em relação aos comportamentos de retaliação organizacional.

\section{Percepção de retaliação organizacional}

Para analisar a estrutura fatorial da escala aplicou-se o método PAF (Principal Axis Factoring), cujos resultados podem ser verificados na Tabela 1 . Apenas um fator significativo (eigenvalue superior a 2,0) emergiu dos dados, nas duas soluções rotadas, identificando apenas uma variável latente subjacente ao construto investigado. Esse fator explica $57 \%$ da variância total e apresenta um coeficiente de fidedignidade de 0,95.

\section{Julgamento da retaliação organizacional}

Para verificar a estrutura dos princípios que organizam as atribuições de justiça em relação à retaliação aplicou-se o método de análise fatorial PAF (Principal Axis Factoring), cujos resultados podem ser vistos na Tabela 2. Apenas um fator significativo (eigenvalue superior a 2,0) emergiu dos dados. Esse fator explica $36 \%$ da variância total e possui o coeficiente de fidedignidade de 0,89. A atribuição de justiça sobre a retaliação organizacional, portanto, possui uma estrutura que se organiza em um único fator, aglutinando itens relacionados à organização e às pessoas que dela fazem parte.

Tabela 1

Resultado da análise fatorial aplicada à escala de percepção de retaliação organizacional

\begin{tabular}{lcc}
\multicolumn{1}{c}{ Item da escala } & Carga & $h^{2}$ \\
& fatorial & 0,74 \\
\hline Alterar a forma de fazer as coisas com o intuito de prejudicar a organização & 0,54 \\
Deixar de colaborar com os colegas de trabalho & 0,73 & 0,53 \\
Influenciar negativamente os colegas de trabalho & 0,76 & 0,57 \\
Fazer corpo mole & 0,79 & 0,62 \\
Negar informações necessárias a um colega & 0,73 & 0,53 \\
Produzir abaixo da capacidade que possui & 0,80 & 0,64 \\
Fingir que está ocupado & 0,76 & 0,58 \\
Ficar indiferente às solicitações feitas pela chefia & 0,71 & 0,51 \\
Gastar mais tempo do intervalo do que o permitido & 0,74 & 0,54 \\
Falar mal da organização para pessoas estranhas ao serviço & 0,80 & 0,64 \\
Descumprir as normas da empresa & 0,74 & 0,55 \\
Tratar com indiferença as pessoas que buscam os serviços prestados pela organização & 0,72 & 0,52 \\
Fazer serviço malfeito de propósito & 0,79 & 0,63 \\
Trabalhar contra a política da empresa & 0,75 & 0,57 \\
Tumultuar o ambiente de trabalho, propositalmente & 0,77 & 0,59 \\
\hline Eigenvalue & 8,59 & - \\
Variância explicada & $57 \%$ & - \\
Coeficiente de fidedignidade (alfa de Cronbach) & 0,95 & - \\
\hline
\end{tabular}

Apenas as cargas fatoriais iguais ou superiores a 0,70 são apresentadas após a rotação varimax Kaiser-Meyer-Olkin = 0,96; Teste de Esfericidade de Bartlett $=1915,81 ; p<0,001$

Método: PAF

Tabela 2

Resultado da análise fatorial aplicada à escala de julgamento da retaliação organizacional

\begin{tabular}{lcc}
\multicolumn{1}{c}{ Item da escala } & $\begin{array}{c}\text { Carga } \\
\text { fatorial }\end{array}$ & $h^{2}$ \\
\hline Alterar a forma de fazer as coisas com o intuito de prejudicar a organização & 0,42 & 0,18 \\
Deixar de colaborar com os colegas de trabalho & 0,46 & 0,20 \\
Influenciar negativamente os colegas de trabalho & 0,64 & 0,41 \\
Fazer corpo mole & 0,68 & 0,48 \\
Negar informações necessárias a um colega & 0,53 & 0,28 \\
Produzir abaixo da capacidade que possui & 0,64 & 0,41 \\
Fingir que está ocupado & 0,68 & 0,46 \\
Ficar indiferente às solicitações feitas pela chefia & 0,62 & 0,38 \\
Gastar mais tempo do intervalo do que o permitido & 0,58 & 0,36 \\
Falar mal da organização para pessoas estranhas ao serviço & 0,61 & 0,37 \\
Descumprir as normas da empresa & 0,54 & 0,35 \\
Tratar com indiferença as pessoas que buscam os serviços prestados pela organização & 0,60 & 0,36 \\
Fazer serviço malfeito de propósito & 0,56 & 0,32 \\
Trabalhar contra a política da empresa & 0,63 & 0,40 \\
Tumultuar o ambiente de trabalho, propositalmente & 0,65 & 0,42 \\
\hline Eigenvalue & 5,35 & - \\
Variância explicada & 35,68 & - \\
Coeficiente de fidedignidade (alfa de Cronbach) & 0,89 & - \\
\hline
\end{tabular}

Kaiser-Meyer-Olkin $=0,96 ;$ Teste de Esfericidade de Bartlett $=1915,81 ; p<0,001$

Método: PAF 


\section{Estudo 2: Análise fatorial confirmatória da Escala de Percepção e Julgamento da Retaliação Organizacional (EPJRO)}

No primeiro estudo foi demonstrada a adequação da EPJRO para avaliar as percepções e os julgamentos que trabalhadores goianienses fazem a respeito da emissão de comportamentos de retaliação nas organizações de trabalho. Este segundo estudo, por sua vez, foi orientado com o objetivo de confirmar, com uma amostra de trabalhadores do serviço público, a estrutura unifatorial obtida no primeiro estudo. Pretende-se submeter à prova a hipótese de que tanto as percepções como os julgamentos sobre a retaliação organizacional são construtos que se estruturam em um único eixo.

\section{Método}

\section{Amostra}

A amostra foi composta por 313 funcionários, cuja idade foi investigada por meio de categorias que variaram de 1 (18 a 25 anos) a 9 (61 a 65 anos), com faixa etária média entre 31 e 40 anos $(37,4 \%)$. A maioria dos participantes era do sexo feminino $(62,3 \%)$, não exerce cargo de chefia $(80 \%)$ e possui tempo de serviço variando de 1 a 20 anos.

\section{Procedimentos}

A aplicação da EPJRO foi realizada como parte de um amplo protocolo de pesquisa. Esse procedimento permitiu o desenvolvimento de uma coleta de dados integrada com outros projetos, racionalizando recursos materiais e otimizando os esforços dos respondentes. Primeiramente, solicitou-se a autorização dos diretores da organização, ficando garantido o anonimato da mesma. O questionário foi administrado individualmente no próprio local de trabalho. Os instrumentos foram distribuídos com um envelope para serem devolvidos lacrados e recolhidos em horários previamente estabelecidos. Foi esclarecido aos participan- tes o caráter estritamente acadêmico da pesquisa e a segurança do sigilo em relação à emissão das respostas.

\section{Resultados}

Com o objetivo de confirmar a validade e a consistência da estrutura fatorial obtida no primeiro estudo, aplicou-se a Análise Fatorial na técnica dos Eixos Principais (PAF - Principal Axis Factoring), que é a técnica estatística recomendada (Pasquali, 1997) para o desenvolvimento de análises com caráter confirmatório.

Assim como no primeiro estudo, os resultados são apresentados em duas seções - referentes à percepção de ao julgamento dos trabalhadores em relação aos comportamentos de retaliação organizacional.

\section{Percepção de retaliação organizacional}

A análise fatorial realizada para a escala de percepção comportamental confirmou a fatorabilidade dos dados disponíveis $(\mathrm{KMO}=0,95$; Teste de esfericidade de Bartlett $=3222,99$; $p<0,001$; communalities variando de 0,44 a 0,67 ).

Os resultados (Tabela 3) obtidos confirmam a solução unifatorial. Apenas um fator significativo (eigenvalue superior a 1,0) emergiu dos dados, identificando uma única variável latente subjacente ao construto investigado. Esse fator explica $56,24 \%$ da variância total e apresenta um coeficiente de fidedignidade de 0,95 .

\section{Julgamento da retaliação organizacional}

Repetiu-se a análise fatorial utilizando-se o método $P A F$ (Principal Axis Factoring) e obtiveram-se bons índices de fatorabilidade $(\mathrm{KMO}=0,93$; Teste de esfericidade de Bartlett $=2405,91, p<0,001 ;$ communalities variando de 0,22 a 0,61). Os resultados (Tabela 4) confirmam a emergência de um único fator com eigenvalue superior a 1 . Esse fator $(\alpha=0,92)$ explica $45,57 \%$ da variância total.

Tabela 3

Resultado da análise fatorial aplicada à escala de percepção de retaliação organizacional

\begin{tabular}{lrc}
\multicolumn{1}{c}{ Item da escala } & $\begin{array}{c}\text { Carga } \\
\text { fatorial }\end{array}$ & $h^{2}$ \\
\hline Alterar a forma de fazer as coisas com o intuito de prejudicar a organização & 0,71 & 0,50 \\
Deixar de colaborar com os colegas de trabalho & 0,71 & 0,50 \\
Influenciar negativamente os colegas de trabalho & 0,79 & 0,61 \\
Fazer corpo mole & 0,78 & 0,61 \\
Negar informações necessárias a um colega & 0,78 & 0,60 \\
Produzir abaixo da capacidade que possui & 0,67 & 0,45 \\
Fingir que está ocupado & 0,75 & 0,51 \\
Ficar indiferente às solicitações feitas pela chefia & 0,78 & 0,60 \\
Gastar mais tempo do intervalo do que o permitido & 0,73 & 0,53 \\
Falar mal da organização para pessoas estranhas ao serviço & 0,72 & 0,52 \\
Descumprir as normas da empresa & 0,76 & 0,58 \\
Tratar com indiferença as pessoas que buscam os serviços prestados pela organização & 0,77 & 0,59 \\
Fazer serviço malfeito de propósito & 0,82 & 0,67 \\
Trabalhar contra a política da empresa & 0,70 & 0,49 \\
Tumultuar o ambiente de trabalho, propositalmente & 0,78 & 0,61 \\
\hline Eigenvalue & 8,44 & - \\
Variância explicada & 56,24 & - \\
Coeficiente de fidedignidade (alfa de Cronbach) & 0,95 & - \\
\hline
\end{tabular}

Kaiser-Meyer-Olkin $=0,95 ;$ Teste de Esfericidade de Bartlett $=3222,99 ; p<0,001$

Método: PAF 
Tabela 4

Resultado da análise fatorial aplicada à escala de julgamento da retaliação organizacional

\begin{tabular}{lrr}
\hline \multicolumn{1}{c}{ Item da escala } & $\begin{array}{c}\text { Carga } \\
\text { fatorial }\end{array}$ & $h^{2}$ \\
\hline Alterar a forma de fazer as coisas com o intuito de prejudicar a organização & 0,47 & 0,22 \\
Deixar de colaborar com os colegas de trabalho & 0,66 & 0,44 \\
Influenciar negativamente os colegas de trabalho & 0,71 & 0,50 \\
Fazer corpo mole & 0,67 & 0,45 \\
Negar informações necessárias a um colega & 0,69 & 0,47 \\
Produzir abaixo da capacidade que possui & 0,64 & 0,41 \\
Fingir que está ocupado & 0,71 & 0,50 \\
Ficar indiferente às solicitações feitas pela chefia & 0,73 & 0,54 \\
Gastar mais tempo do intervalo do que o permitido & 0,62 & 0,39 \\
Falar mal da organização para pessoas estranhas ao serviço & 0,70 & 0,48 \\
Descumprir as normas da empresa & 0,66 & 0,44 \\
Tratar com indiferença as pessoas que buscam os serviços prestados pela organização & 0,65 & 0,42 \\
Fazer serviço malfeito de propósito & 0,78 & 0,61 \\
Trabalhar contra a política da empresa & 0,62 & 0,38 \\
Tumultuar o ambiente de trabalho, propositalmente & 0,74 & 0,56 \\
\hline Eigenvalue & 6,83 & - \\
Variância explicada & 45,53 & - \\
Coeficiente de fidedignidade (alfa de Cronbach) & 0,92 & - \\
\hline
\end{tabular}

Kaiser-Meyer-Olkin $=0,93 ;$ Teste de Esfericidade de Bartlett $=2405,91 ; p<0,001$

Método: PAF

\section{Conclusões}

Em consonância com os resultados obtidos no estudo de Skarlicki e Folger (1997), as análises realizadas nos dois estudos confirmaram que os 15 itens obtidos que compõem a forma final da escala configuram-se em apenas um componente principal. Assim, as reações retaliatórias organizam-se em um único eixo, o que implica dizer que a retaliação ocorre de maneira ampla e geral no contexto organizacional. Não se estrutura, portanto, direcionada exclusivamente à organização ou às pessoas que dela fazem parte.

Este estudo avança de uma concepção puramente comportamental para uma concepção que abarca dimensões perceptivas e avaliativas acerca da retaliação organizacional. Com essa metodologia é possível analisar os comportamentos disfuncionais que são suscetíveis ao problema da desejabilidade social.

Os dados comparativos entre as três medidas desenvolvidas neste estudo, comportamental, de intenção e de percepção e julgamento, demonstram que os trabalhadores não assumem que retaliam e nem que têm vontade de retaliar, mas percebem que a retaliação ocorre no ambiente de trabalho e se posicionam de maneira avaliativa sobre a emissão desses comportamentos. Diante do temor do desemprego vivido no atual contexto socioeconômico, é pouco provável que se possam investigar comportamentos disfuncionais utilizando medidas comportamentais diretas.

Este estudo permite investigar duas dimensões distintamente importantes: se a retaliação ocorre na instituição e qual a avaliação que os empregados fazem acerca desses comportamentos. Ao investigar a ocorrência da retaliação no trabalho e compreender a avaliação que os empregados fazem desses comportamentos, esta escala pode ser utilizada como uma ferramenta de diagnóstico organizacional.
Conhecer a realidade organizacional por meio da percepção das pessoas que compõem o quadro funcional permite delinear um diagnóstico real do contexto. Ademais, a manifestação de ser favorável ou não em relação à emissão de comportamentos de retaliação possibilita aos gestores propor estratégias de intervenção organizacional que favorecem a supressão de ações negativas, como a retaliação.

Entretanto, não foi objetivo deste estudo investigar os antecedentes da retaliação. Espera-se que esta escala possa contribuir para que pesquisadores interessados no assunto desenvolvam investigações que permitam compreender as variáveis idiossincráticas e contextuais que antecedem a retaliação organizacional.

Espera-se, também, que esta escala seja um instrumento útil para compreender como a retaliação pode afetar a eficácia organizacional e prejudicar a manutenção de comportamentos socialmente aceitos, especialmente aqueles inovadores e espontâneos, não prescritos nos papéis organizacionais.

\section{Referências}

Adams, J. S. (1965). Inequity in social exchange. In L. Berkowitz (Org.), Advances in experimental social psychology (Vol. 2). Nova York: Academic. Allport, G. W., Vernon, P., \& Lindsey, G. (1960). Study of values: manual. Boston: Houghton Miffin.

Fiske, S. T., \& Taylor, S. E. (1991). Social cognition. Nova York: McGraw-Hill. Flanagan, J. C. (1954). The critical incident technique. Psychological Bulletin, 51, 327-358.

Gomide Jr., S. (1999). Antecedentes e conseqüentes das percepções de justiça no trabalho. Tese de Doutorado não-publicada, Universidade de Brasília, Brasília.

Hollinger, R. C., \& Clark, J. P. (1983). Theft by employees. Lexington: Lexington Books.

Homans, G. C. (1961). Social behavior: its elementary forms. Nova York: Harcourt, Brace \& World. 
James, L., \& James, L. (1989). Integrating work environment perceptions: explorations into the measurement of meaning. Journal of Applied Psychology, 74, 739-751.

Jermier, J. M., Knights, D., \& Nord, W. (1994). Resistance and power in organizations. Londres: Routledge.

Lewin, K. (1935). A dynamic theory of personality. Nova York: McGraw-Hill.

McEvoy, G. M., \& Buller, P. (1987). User acceptance of peer appraisals in an industrial setting. Personnel Psychology, 40, 785-797.

Mowday, R. T., Poter, L. W., \& Steers, R. M. (1982). Employee organizations linkages. Nova York: Academic.

Murphy, K. R. (1993). Honesty in the workplace. Pacific Grove, Califórnia: Brooks/Cole.

Pasquali, L. (1997). Psicometria: teoria e aplicações. Brasília: Editora da UnB.

Robbins, S. P. (1999). Valores, atitudes e satisfação no trabalho. In S. P. Robbins (Org.), Comportamento organizacional (pp. 85-106). Rio de Janeiro: LTC.
Schneider, B. (1985). Organizational behavior. Annual Review of Psychology, 36, 573-611.

Siqueira, M. M. M. (1995). Antecedentes de comportamento de cidadania organizacional: a análise de um modelo pós-cognitivo. Tese de Doutorado não-publicada, Universidade de Brasília, Brasília.

Siqueira, M. M. M., \& Pereira, S. E. F. S. (2001). Análise de um modelo afetivo para intenção de sair da organização. Manuscrito não-publicado, Universidade Federal de Uberlândia, Uberlândia.

Skarlicki, D. P., \& Folger, R. (1997). Retaliation in the workplace: the roles of distributive, procedural, and interactional justice. Journal of Applied Psychology, 82(3), 434-443.

Skarlicki, D. P., Folger R., \& Tesluk, P. (1999). Personality as a moderator in the relationship between fairness and retaliation. Academy of Management Journal, 42, 100-108.

1 A palavra ineqüidade é utilizada na literatura sobre justiça para representar o que não é eqüitativo, que pode ser, por exemplo, uma distribuição com base no princípio da igualdade ou da necessidade. Portanto, com base no princípio utilizado é justo, mas não é eqüitativo. A iniqüidade, por sua vez, é sinônimo de injustiça.

Helenides Mendonça, doutora em Psicologia pelo Instituto de Psicologia da UnB, é professora e diretora do Curso de Psicologia da Universidade Católica de Goiás. Endereço para correspondência: Av. 85, n. 300, apto 402-A (Setor Marista); Goiânia, GO; CEP 74160-010. Tel.: 227-1097. E-mail: helenides@ uol.com.br

Dulce Pires Flauzino, doutora em Psicologia pelo Instituto de Psicologia da UnB, é professora da Universidade Federal de Uberlândia. E-mail: flauzinop@ uol.com.br

Álvaro Tamayo, pós-doutor em Psicologia pela Université de Moncton (Canadá), é professor titular no Instituto de Psicologia da UnB. E-mail: tamayo@terra.com.br

Maria das Graças Torres Paz, doutora em Psicologia pela Universidade de São Paulo, é professora no Instituto de Psicologia da UnB. E-mail: torrespaz@uol.com.br 


\section{Apêndice}

Alguns estudos sugerem que quando as pessoas são tratadas injustamente no trabalho tendem a reagir contra-atacando de algum modo.

Agora, pensando na sua experiência e no seu trabalho atual, pedimos que leia atentamente as frases abaixo e responda cada uma das colunas escrevendo o número que melhor representa a sua sincera opinião.

\begin{tabular}{|c|c|c|}
\hline & \\
\hline & $1^{\mathrm{a}}$. COLUNA & $2^{\text {a. }}$ COLUNA \\
\hline & \begin{tabular}{|c|} 
nunca \\
poucas vezes \\
algumas vezes \\
muitas vezes \\
sempre
\end{tabular} & \begin{tabular}{|c|} 
muito injusto \\
injusto \\
nem injusto e nem justo \\
justo \\
justíssimo
\end{tabular} \\
\hline & $\begin{array}{l}\text { Qual a frequêência com que } \\
\text { as pessoas da sua } \\
\text { organização, ao se sentirem } \\
\text { injustiçadas, costumam se } \\
\text { comportar da forma descrita } \\
\text { nas frases abaixo? }\end{array}$ & $\begin{array}{l}\text { Agora, considere você e } \\
\text { julgue como justo ou injusto } \\
\text { os comportamentos descritos } \\
\text { nas frases, quando as pessoas } \\
\text { sofrem injustiças no } \\
\text { trabalho. }\end{array}$ \\
\hline \multicolumn{3}{|l|}{$\begin{array}{l}\text { 1. Alterar a forma de fazer as coisas com o } \\
\text { intuito de prejudicar a organização }\end{array}$} \\
\hline \multicolumn{3}{|l|}{$\begin{array}{l}\text { 2. Deixar de colaborar com os colegas de } \\
\text { trabalho }\end{array}$} \\
\hline \multicolumn{3}{|l|}{$\begin{array}{l}\text { 3. Influenciar negativamente os colegas de } \\
\text { trabalho }\end{array}$} \\
\hline \multicolumn{3}{|l|}{ 4. Fazer corpo mole } \\
\hline \multicolumn{3}{|l|}{ 5. Negar informações necessárias a um colega } \\
\hline \multicolumn{3}{|l|}{ 6. Produzir abaixo da capacidade que possui } \\
\hline \multicolumn{3}{|l|}{ 7. Fingir que está ocupado } \\
\hline \multicolumn{3}{|l|}{$\begin{array}{l}\text { 8. Ficar indiferente às solicitações feitas pela } \\
\text { chefia }\end{array}$} \\
\hline \multicolumn{3}{|l|}{$\begin{array}{l}\text { 9. Gastar mais tempo de intervalo do que o } \\
\text { permitido }\end{array}$} \\
\hline \multicolumn{3}{|l|}{$\begin{array}{l}\text { 10. Falar mal da organização para pessoas } \\
\text { estranhas ao serviço }\end{array}$} \\
\hline \multicolumn{3}{|l|}{ 11. Descumprir as normas da empresa } \\
\hline \multicolumn{3}{|l|}{$\begin{array}{l}\text { 12. Tratar com indiferença as pessoas que } \\
\text { buscam os serviços prestados pela } \\
\text { organização }\end{array}$} \\
\hline \multicolumn{3}{|l|}{ 13. Fazer o serviço malfeito de propósito } \\
\hline \multicolumn{3}{|l|}{ 14. Trabalhar contra a política da empresa } \\
\hline $\begin{array}{l}\text { 15. Tumultuar o ambiente de trabalho, } \\
\text { propositalmente }\end{array}$ & & \\
\hline
\end{tabular}

